\title{
THRESHING AND GRAIN SEPARATING MECHANISM WITH DIFFERENTIATE CONCAVE FOR INTENSIFICATION OF THRESHING AND GRAIN SEPARATION
}

\author{
Aleksandr Viktorovich Klochkov ${ }^{\mathrm{a}}$, Vladimir Vladimirovich Gusarov ${ }^{\mathrm{a}}$, Maciej Kuboń ${ }^{\mathrm{b}}$, \\ Jan Radosław Kamiński ${ }^{\text {c }^{*}}$ \\ ${ }^{a}$ Belorussian Agricultural Academy, Gorki, Mogilev Region, Belarus \\ ${ }^{\mathrm{b}}$ Institute of Agricultural Engineering and Informatics, University of Agriculture in Kraków \\ ${ }^{\mathrm{c}}$ Department of Agricultural and Forest Machinery, Warsaw University of Life Sciences - SGGW \\ "Corresponding author: e-mail: jan_kaminski@sggw.pl
}

\begin{tabular}{|c|c|}
\hline ARTICLE INFO & ABSTRACT \\
\hline $\begin{array}{l}\text { Article history: } \\
\text { Received: May } 2017 \\
\text { Received in the revised form: } \\
\text { July } 2017 \\
\text { Accepted: August } 2017 \\
\end{array}$ & \multirow[b]{2}{*}{$\begin{array}{l}\text { The objective of the paper was intensification of the process of thresh- } \\
\text { ing and grain separation by a rasp-bar threshing mechanism of } \\
\text { a combine harvester with a differentiate concave; substantiation of } \\
\text { a regular-style design and differentiate concave parameters as well as } \\
\text { threshing and separating mechanism operation modes. Theoretical } \\
\text { research has been conducted based on laws of motion, experimental } \\
\text { investigation - in accordance with methods devised on the basis of } \\
\text { conventional methodologies. Standard computing methods as well as } \\
\text { Microsoft Excel and Mathcad application packages have been used for } \\
\text { processing experimental data. Measuring and recording equipment has } \\
\text { been used in the research process. Experimental investigation has been } \\
\text { carried out on specially devised experimental assemblies. The research } \\
\text { has enabled: to substantiate the design-manufacturing process of the } \\
\text { threshing and separating mechanism with a differentiate concave; to } \\
\text { establish analytical dependencies to determine the area of typical } \\
\text { influence zones of a threshing drum and concave on threshing mass; to } \\
\text { ascertain the regularity of stem deformation under the influence of } \\
\text { different forces regulated by changing the distance between concave } \\
\text { transverse slats; to figure out the regression equation enabling finding } \\
\text { optimal process variables for a threshing and separating mechanism } \\
\text { with a differentiate concave. The scientific novelty of the engineering } \\
\text { solutions is confirmed by a patent of the Republic of Belarus for the } \\
\text { utility model № } 6335 \text { « Tresking mechanism». The results of theoreti- } \\
\text { cal and experimental research have been used in developing design } \\
\text { documentation for the production of a differentiate concave for com- } \\
\text { bine harvesters PA «Gomselmash». }\end{array}$} \\
\hline $\begin{array}{l}\text { Key words: } \\
\text { combine harvester, } \\
\text { threshing and separating mechanism, } \\
\text { differentiate concave, } \\
\text { threshing, } \\
\text { separation }\end{array}$ & \\
\hline
\end{tabular}

\section{Введение}

Среди этапов сельскохозяйственного производства доминирующее положение (50-55\%) по затратам материально-технических и энергетических ресурсов занимает уборка урожая, особенно зерновых культур. Во всех странах мира основным 
средством уборки зерновых культур является зерноуборочный комбайн. При современных технологиях уборки зерна одним из условий эффективной работы является наличие достаточного количества высокопроизводительных комбайнов для уборки урожая зерна в установленные агротехнические сроки (Golka (red.) 2016; Kamiński (red.) 2011; Kamiński i in. 2015).

Исследованию процесса обмолота, его закономерностей, технической реализации посвящено большое количество научных работ (Bułgakov и др. 2006; Dębska и др. 2016; Клочков и др. 2008; 2009; 2012; Knapik 1994; Letoszniew 1953; Липкович 2004; Miłosz 2000; Molendowski 2001; 2006; Molendowski и др. 2011a; 2011b; 2012; Mulka и др. 1996; Szymanek, Dreszer 2011; Зайцев 2002).

В результате анализа литературных источников установлено, что важным элементом МСУ является подбарабанье, конструкция которого существенно влияет на интенсивность обмолота и сепарации зерна. Это обусловлено следующими факторами: во-первых, потери за соломотрясом (следующим звеном технологической цепи) пропорциональны количеству поступившего на него зерна и зависят от степени перебивания (измельчения) соломы; во-вторых, конструкция подбарабанья определяет количество в сепарируемом ворохе нежелательных компонентов: соломы, сбоины, сорных примесей, увеличение количества которых влечет за собой рост потерь за системой очистки комбайна.

\section{Цель и задачи исследования.}

Целью исследований является интенсификация процесса обмолота и сепарации зерна молотильно-сепарирующим устройством (МСУ) с дифференцированным подбарабаньем.

Обоснование рациональной конструкции, параметров дифференцированного подбарабанья и режимов работы МСУ позволит интенсифицировать обмолот массы и сепарацию зерна, увеличить производительность зерноуборочного комбайна и уменьшить удельные энергозатраты на обмолот, а в конечном итоге - повысить эффективность уборки зерна.

Для достижения данной цели необходимо:

- обосновать конструктивно-технологическую схему МСУ с дифференцированным подбарабаньем, обеспечивающим увеличение сепарации вымолоченного зерна через подбарабанье, снижение энергозатрат на выделение зерна из колосьев с выполнением качественных требований, предъявляемых к обмолоту сельскохозяйственных культур зерноуборочными комбайнами;

- изучить характеристики деформации обмолачиваемых стеблей и требуемые энергозатраты;

- исследовать и обосновать основные параметры дифференцированного подбарабанья;

- исследовать процесс обмолота и сепарации зерна МСУ с дифференцированным подбарабаньем, проведя анализ его основных параметров и режима работы: приведенной подачи массы, скорости бичей молотильного барабана, зазоров между молотильным барабаном и подбарабаньем; 
Threshing and grain separating...

- экспериментально уточнить и подтвердить достоверность результатов теоретических исследований рабочего процесса МСУ с дифференцированным подбарабаньем;

- определить параметр оптимизации, выявить действующие факторы и по результатам опытов построить модель процесса обмолота и сепарации, провести оценку модели;

- реализовать полученные результаты теоретических и экспериментальных исследований в конструкции МСУ конкретного комбайна и определить экономическую эффективность его использования при уборке сельскохозяйственных культур.

Объектом исследований был МСУ с дифференцированным подбарабаньем.

Предметом исследований был процесс обмолота и сепарации зерна МСУ, основные параметры дифференцированного подбарабанья и режимы работы МСУ.

\section{Теоретический анализ}

Рассмотрены особенности движения обмолачиваемой массы в молотильном зазоре. Установлено, что характер движения обмолачиваемой массы вдоль подбарабанья является не непрерывным, а имеет порционно-прерывистый характер движения. Масса, проходя в зазоре, подвергается ударно-перетирающему и изгибающему воздействию бичей барабана и планок подбарабанья. При этом в различных зонах молотильного зазора обмолачиваемая масса испытывает различные воздействия (рисунок 1). Окружное усилие, действующее на элементы конструкции МСУ, можно определить по уточненной формуле академика В. П. Горячкина (Гусаров и др. 2015):

$$
P=\frac{\mathrm{M}^{\prime} \cdot v_{\mathrm{M}}}{1-f}
$$

где:

M' - масса порции, приведенная к единице времени, кг· $\mathrm{c}^{-1}$

$v_{\mathrm{m}} \quad$ - средняя скорость движения порции обмолачиваемой массы в молотильном зазоре, $\mathrm{M}^{-1}$

$f \quad$ - коэффициент перетирания соломы.

Часть (порция) обмолачиваемой массы (M), находящаяся между серединами соседних бичей барабана, по зонам расположения в молотильном зазоре может быть представлена следующими составляющими:

$$
\mathrm{M}=\left(S_{1}+S_{2}+S_{3}+S_{4}\right) L_{6} \gamma_{\mathrm{cp}}
$$

где:

$S_{1} \quad$ - площадь сечения, занимаемая массой в промежутке между бичами барабана и планками подбарабанья, подвергающейся преимущественно ударно-перетирающему воздействию, м²

$S_{2} \quad-$ площадь сечения, занимаемая массой в верхней части промежутка между бичами барабана, подвергающейся преимущественно ударноизгибающему воздействию, м $^{2}$ 
$S_{3} \quad-$ площадь сечения, занимаемая массой в нижней части промежутка между бичами барабана, подвергающейся преимущественно перетирающему и ударно-изгибающему воздействиям, ${ }^{2}$

$S_{4} \quad$ - площадь сечения, занимаемая массой в промежутке между планками подбарабанья, подвергающейся преимущественно ударно-изгибающему воздействию, м²

$L_{\sigma} \quad$ - рабочая длина молотильного барабана, м

$\gamma_{\mathrm{cp}}$ - среднее значение объемной массы материала, находящегося в зоне

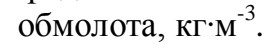

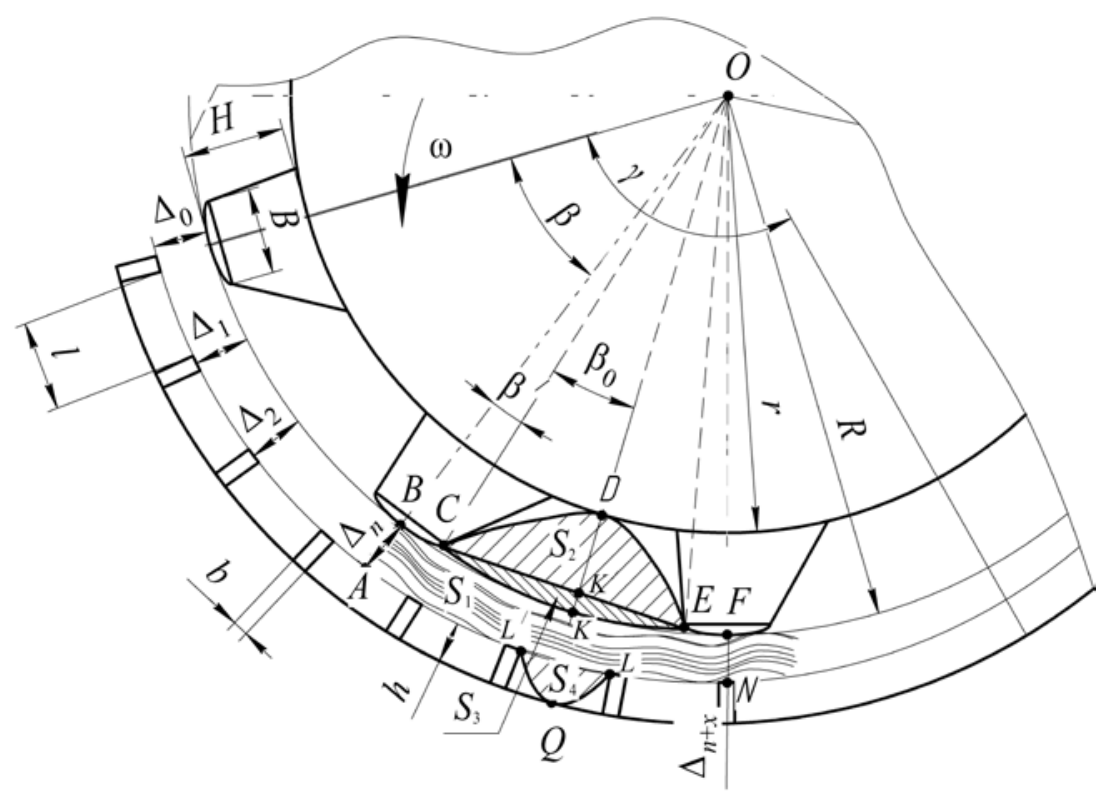

Рисунок 1. Схема к определению площадей сечений характерных зон воздействия на обмолачиваемую массу

Источник: Разработка авторов.

Пользуясь выражениями (3), (4) и (5), можно вычислить площади таких зон, как $S_{2}, S_{3}, S_{4}$, которые определяются по известным размерным параметрам МСУ:

$$
\begin{gathered}
S_{2}=\frac{1}{2} \sqrt{2 R^{2}-2 R^{2} \cdot \cos 2 \beta_{0}} \cdot\left((R-r)-\left(R\left(1-\cos \beta_{0}\right)\right) ;\right. \\
S_{3}=\frac{1}{2} \sqrt{2 R^{2}-2 R^{2} \cdot \cos 2 \beta_{0}} \cdot\left(R\left(1-\cos \beta_{0}\right)\right) ; \\
S_{4}=\frac{1}{2} l_{i} \cdot h_{i},
\end{gathered}
$$


Threshing and grain separating...

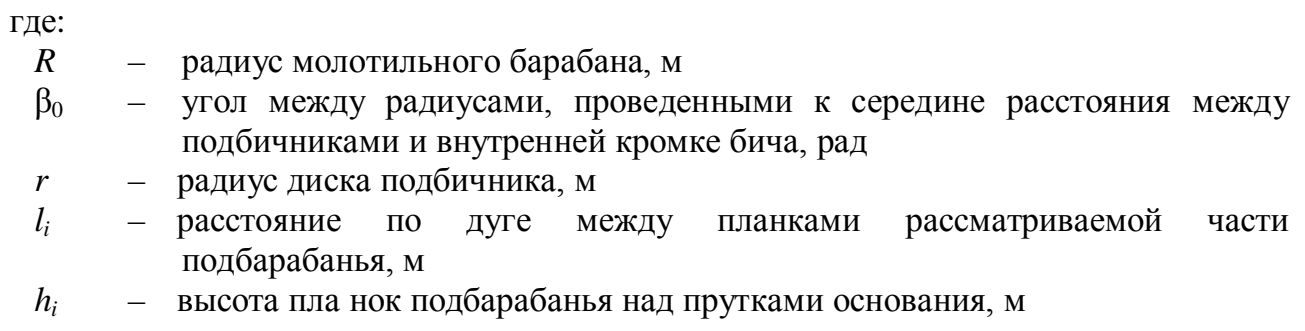

В пределах площади $S_{1}$ масса испытывает ударно-перетирающее воздействие при различных скоростях движения слоев материала.

Эта площадь в направлении вращения барабана будет постоянно изменяться в сторону уменьшения. Обусловлено это клинообразным зазором между барабаном радиусом $R$ с центром в точке $O$ и подбарабаньем радиусом $R_{1}$ с центром в точке $O_{1}$, смещенной относительно точки $O$ вдоль оси $y$ на величину $a$ и вдоль оси $x$ на величину $b$ (Рисунок 2).

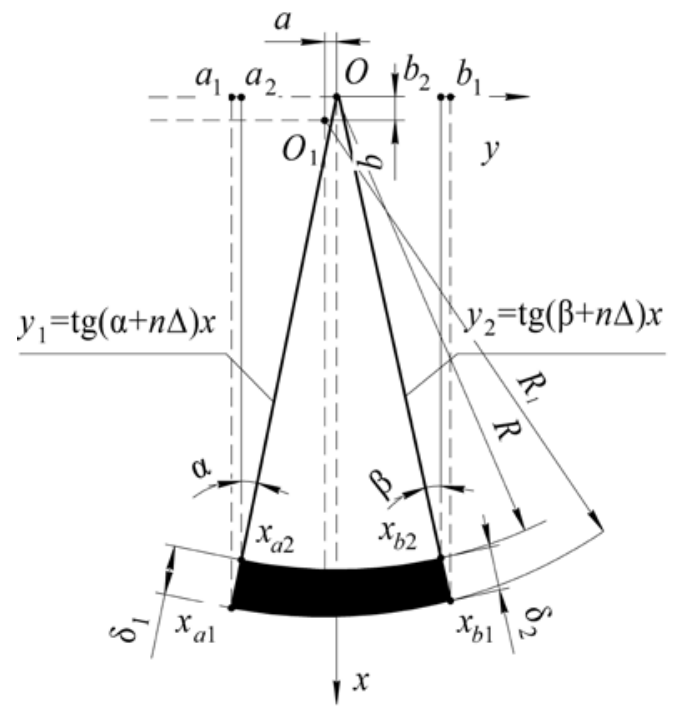

Рисунок 2. Схема для определения площฺади $S_{1}$

Источник: Разработка авторов.

Площадь $S_{1}$ образуется в результате пересечения двух прямых $y_{1}=\operatorname{tg}(\alpha+n \Delta) x$ и $y_{2}=\operatorname{tg}(\beta+n \Delta) x$, выходящих из центра вращения молотильного барабана, с окружностями радиусом $R$ и $R_{1}$, где $\alpha$ и $\beta$ - углы наклона соответственно прямых $y_{1}$ и $y_{2}$ к оси $x$, рад; $n$ - количество секторов; $\Delta$ - шаг изменения угла в радианах (площадь сектора изменяется с шагом 0,017 рад $=1^{\circ}$ от $\alpha=\frac{\pi}{2}$ до $\beta=\frac{2 \pi}{5}$ ) (7). 
В результате этого пересечения образованы точки $x_{a 1}, x_{a 2}, x_{b 1}$ и $x_{b 2}$. Формула для определения площади $S_{1}$ в зависимости от угла поворота молотильного барабана имеет вид

$$
S_{1}=S_{a_{1} x_{a 1} x_{b 1} b_{1}}-S_{a_{2} x_{a 2} x_{b 2} b_{2}}-S_{a_{1} x_{a 1} x_{a 2} a_{2}}-S_{b_{1} x_{b 1} x_{b 2} b_{2}}
$$

Каждая из площадей определяется зависимостью:

$$
\begin{gathered}
S_{a_{1} x_{a 1} x_{b 1} b_{1}}=\int_{b_{1}}^{a_{1}} f_{2}\left(x_{1}\right) d x ; \\
S_{a_{2} x_{a 2} x_{b 2} b_{2}}=\int_{b_{2}}^{b_{1}} f_{1}\left(x_{1}\right) d x ; \\
S_{a_{1} x_{a 1} x_{a 2} a_{2}}=\frac{f_{2}\left(a_{1}\right)+f_{1}\left(a_{2}\right)}{2} \cdot\left(a_{1}-a_{2}\right) ; \\
S_{b_{1} x_{b 1} x_{b 2} b_{2}}=\frac{f_{2}\left(b_{1}\right)+f_{1}\left(b_{2}\right)}{2} \cdot\left(b_{1}-b_{2}\right) .
\end{gathered}
$$

Подставив выражения (7), (8), (9) и (10) в выражение (6), получим выражение для определения площади $S_{1}$ :

$$
\begin{gathered}
S_{1}=\int_{b_{1}}^{a_{1}} f_{2}\left(x_{1}\right) d x-\int_{b_{2}}^{b_{1}} f_{1}\left(x_{1}\right) d x-\frac{f_{2}\left(a_{1}\right)+f_{1}\left(a_{2}\right)}{2} \cdot\left(a_{1}-a_{2}\right)- \\
-\frac{f_{2}\left(b_{1}\right)+f_{1}\left(b_{2}\right)}{2} \cdot\left(b_{1}-b_{2}\right),
\end{gathered}
$$

где:

$a_{1}, a_{2}, b_{1}$ и $b_{2}-$ пределы интегрирования (постоянно изменяющиеся при вращении молотильного барабана координаты данных точек по оси $x$ ), м

Скорость движения порции массы $v_{\mathrm{M}}$, вдоль подбарабанья можно определить по выражению

$$
v_{\mathrm{M}}=B_{\text {ж }} \cdot v_{\mathrm{\kappa}} \cdot U / L_{\sigma} \cdot \Delta_{\mathrm{cp}} \cdot \gamma_{\mathrm{cp}},
$$

где:

$B_{\text {ж }} \quad$ - ширина захвата жатки, м

$v_{\mathrm{\kappa}} \quad$ - скорость движения комбайна, м'с ${ }^{-1}$

$U$ - урожайность растительной массы, кг· $\mathrm{M}^{-2}$

$\Delta_{\mathrm{cp}} \quad$ - среднее значение молотильного зазора, м

После приведения к единице времени значения массы порции М и подстановки в выражение (1) средней скорости движения порции массы в молотильном зазоре $v_{\mathrm{m}}$ значение окружного усилия равно 
Threshing and grain separating...

$$
P=\frac{\left(S_{1}+S_{2}+S_{3}+S_{4}\right) \cdot k \cdot v_{6} \cdot B_{ж} \cdot v_{\mathrm{K}} \cdot U}{\pi \cdot D \cdot \Delta_{\mathrm{cp}} \cdot(1-f)},
$$

где:

$k-$ - число бичей молотильного барана

$v_{\sigma} \quad$ - скорость бичей молотильного барабана, м c $^{-1}$

$D \quad$ - диаметр молотильного барабана, м

Значением окружного усилия, определенным по данному выражению, можно пользоваться при определении параметров МСУ на стадии проектирования.

Выражение для определения числа поперечных планок, дифференцированного подбарабанья, имеет вид

$$
n_{\mathrm{n}}=\frac{\pi \cdot R_{1} \cdot \beta_{\mathrm{ox}}}{360}\left(\frac{1}{l_{\min }+b}+\frac{1}{l_{\max }+b}\right),
$$

где:

$R_{1} \quad-$ радиус кривизны подбарабанья, м

$\beta_{\text {ох }} \quad-$ угол охвата подбарабанья, рад

$l_{\min }$ - нижняя граница интервала изменения расстояния между поперечными планками, м

b $\quad$ - ширина планки, м

$l_{\max } \quad$ верхняя граница интервала изменения расстояния между поперечными планками, м

Выражение для определения минимального расстояния, между поперечными планками дифференцированного подбарабанья, имеет вид

$$
l_{\text {imin }}=\frac{\frac{2 \cdot L_{\mathrm{n}}}{n_{\mathrm{n}}}-d_{l} \cdot\left(n_{\mathrm{n}}-1\right)}{2},
$$

где:

$L_{\text {п }} \quad$ - длина подбарабанья, м

$d_{l} \quad$ - шаг изменения расстояния между поперечными планками, м

Выражение для определения максимальной высоты поперечной планки относительно продольных прутков имеет вид

$$
h_{\max }=\frac{2 \Delta S_{1}+d_{h}\left(l_{2}+2 l_{3}+\ldots+(n-1) l_{n}\right)}{l_{1}+l_{2}+\ldots+l_{n}},
$$

где:

$\Delta S_{1} \quad$ - изменение площади сечения $S_{1}$ от максимального значения $S_{1 \max }$ в зоне входа в МСУ до минимального $S_{1 \min }$ в зоне выхода из МСУ, м²

$d_{h} \quad-$ шаг изменения высоты поперечных планок, м

$l_{1}, l_{2}, \ldots, l_{n}$ - расстояния между поперечными планками, м

$n$ - число поперечных планок, находящихся между серединами соседних бичей. 
A.V. Klochkov, V.V. Gusarov, M. Kuboń, J.R. Kamiński

Полученые аналитические зависимости позволяют вычислить основные конструкторские параметры дифференцированного подбарабания после экспериментального определения диапазона изменения растояния между поперечными планками.

\section{Програма, методика и результаты лабораторных исследований}

Конструкция предлагаемого МСУ с дифференцированным подбарабанием показана на рисунке 3, отличается особенностью, что расстояния l, между поперечными планками 4 уменьшаются от входа к выходу из подбарабания, а высота $\mathrm{h}_{\mathrm{i}}$ поперечных планок относительно продольных прутков 3 увеличивается. За счет этих изменяющихся параметров повышается степень изгиба слоя движущейся массы, что облегчает прцесс выделения из нее зерен и повышает полноту их выделения.
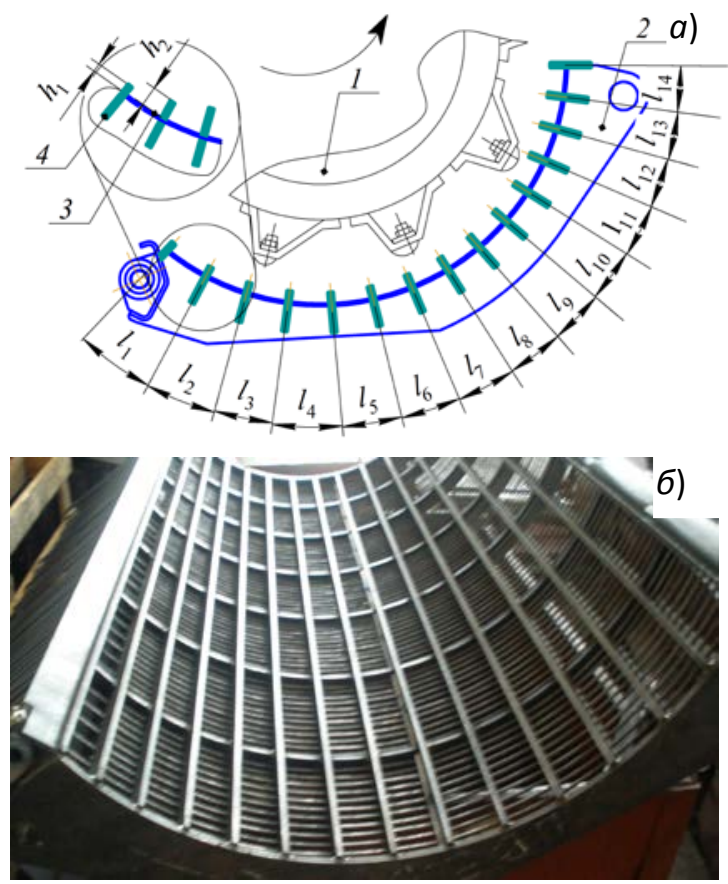

Рисунок 3. Дифференцированное подбарабанье: а - схема дифференцированного подбарабанья; б - общий вид; 1 - молотильный барабан; 2 - подбарабанье; 3- пруток; 4 - планка.

Источник: Разработка авторов.

Приведены программы и методики лабораторных и производственных исследований определения деформации стеблей между планками подбарабанья и процесса обмолота и сепарации зерна МСУ с дифференцированным подбарабаньем. 
Threshing and grain separating...

Программой лабораторных исследований предусматривалось разработать конструкцию молотильного аппарата с использованием преимуществ дифференцированного подбарабанья. Исследовать параметры деформации обмолачиваемого материала на рабочей поверхности подбарабанья, определить интервалы варьирования значений основных факторов, влияющих на процесс обмолота и сепарации зерна МСУ с дифференцированным подбарабаньем, а также определить рациональные параметры предлагаемой конструкции подбарабанья и получить математическую модель процесса обмолота и сепарации.

Этапы экспериментов в производственных условиях предусматривали проверку результатов теоретических и экспериментальных исследований в производственных условиях, проведение сравнительных испытаний зерноуборочных комбайнов с серийным и дифференцированным подбарабаньем.

Исследования процесса обмолота и сепарации, а также влияния параметров МСУ на качественные показатели его работы проводились на специально созданной лабораторной установке (рисунок 4) (Гусаров и др. 2015).

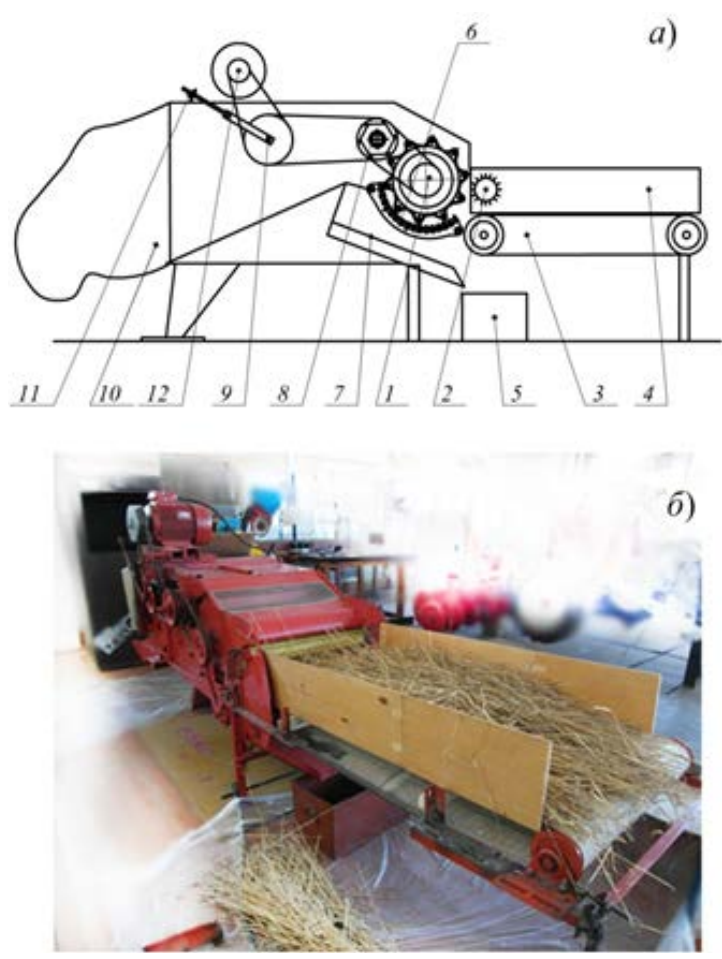

Рисунок 4. Схема и общий вид установки а - схема установки; б - общий вид установки; 1 - молотильный барабан; 2 - подающий битер; 3 транспортер; 4 - ограждение; 5 емкость для сбора массы, прошедшей через подбарабанье; 6 подбарабанье; 7 - лоток; 8 отбойный битер; 9 - клиноременный вариатор; 10 - мешок для сбора соломы; 11 - винт регулировки оборотов; 12 - электродвигатель.

Источник: Разработка авторов. 
При исследованиях деформации стеблей установлено, что изгиб стеблей в значительной степени зависит от расстояния между планками подбарабанья. По усредненным данным, удельные энергозатраты на изгиб стеблей более значительны при расстоянии между планками (50-80) $10^{-3}$ м и составляют (2-10) $10^{-3}$ Дж· ${ }^{-1}$. При увеличении расстояния между планками свыше (90-120)·10 $10^{-3}$ м энергозатраты стабилизируются на уровне до $(1,5-2,0) \cdot 10^{-3}$ Дж· $\mathrm{M}^{-1}$ (Рисунок 5).

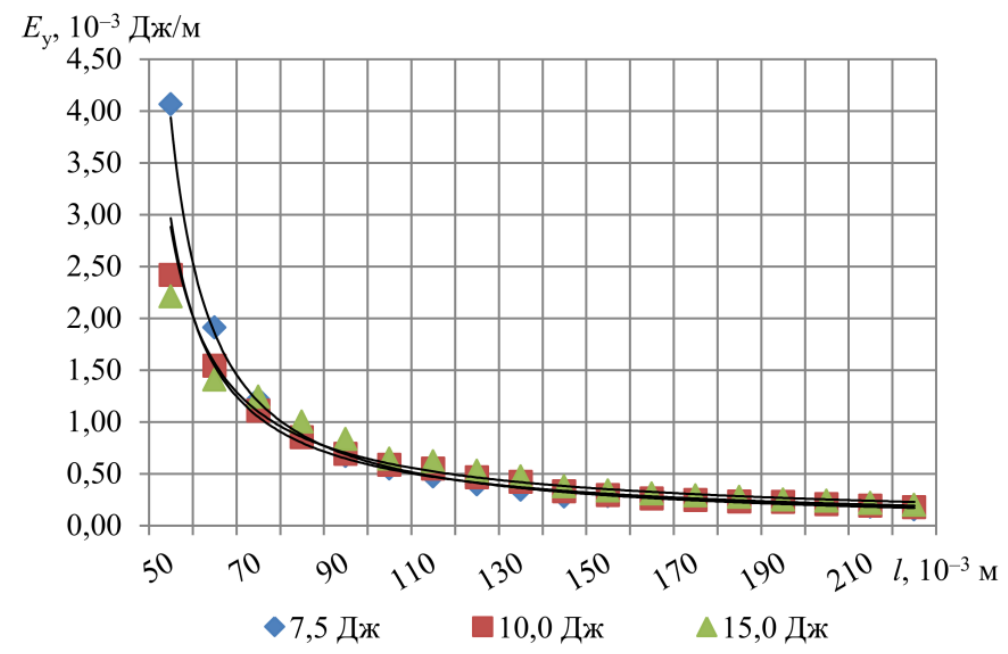

Рисунок 5. Зависимости удельньх энергозатрат на деформащию стеблей Еу при случайном расположении стеблей от расстояния между планками I

Источник: Разработано авторами на основе собственных исследований.

Установленный интервал изменения расстояний между поперечными планками подбарабания позволил определить по выражению (14) число планок дифференцированного подбарабания $\left(\mathrm{n}_{\mathrm{u}}=15\right)$. По выражению (15) определено минимальное расстояние между поперечными планка-ми $\left(\mathrm{l}_{\mathrm{i} \min }=53,3 \cdot 10^{-3} \mathrm{M}\right)$ при шаге изменения расстояния между ними $\mathrm{d}_{\mathrm{i}}=2 \cdot 10^{-3} \mathrm{M}$. По выражению (16) определена максимальная высота поперечной планки относительно продольных прутков $\mathrm{h}_{\max }=26 \cdot 10^{-3}$ м. В ходе однофакторных экспериментов исследованы три подбарабания с различными рабочими поверхностями, образованными поперечными планками и прутками.

В варианте «Подбара-банье 1», имеющем дифференцированную рабочую поверхность (рисунок 6, a), высота планок относительно прутков от входа к выходу

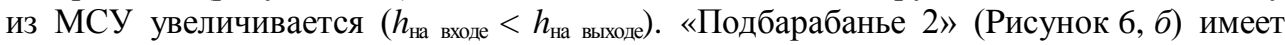
одинаковую высоту планок относительно прутков $\left(h_{\text {навходе }}=h_{\text {на выходе }}\right)$. В варианте «Подбарабанье 3» (Рисунок 6, в), также имеющем дифференцированную поверхность, высота планок относительно прутков от входа к выходу уменьшается $\left(h_{\text {навходе }}>h_{\text {на }}\right.$ выходе). 
Threshing and grain separating...

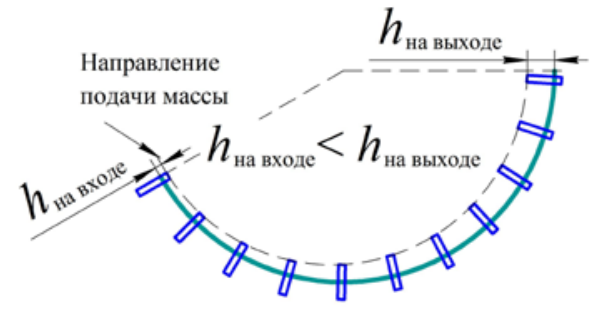

a)

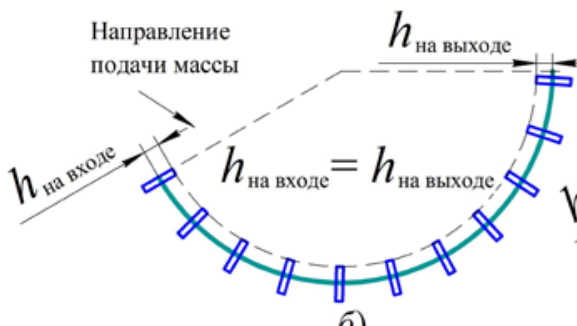

б)

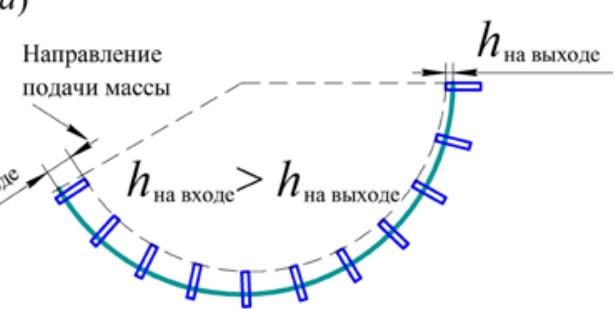

в)

a - подбарабанье с увеличивающейся высотой планок относительно прутков от входа к выходу из МСУ; б - серийное подбарабанье с постоянными параметрами планок; в - подбарабанье с уменьшающейся высотой планок относительно прутков от входа к выходу из МСУ.

Рисунок 6. Схемы исследуемых подбарабаний

Источник: Разработано авторами.

Установлено, что подбарабанья с дифференцированной рабочей поверхностью («Подбарабанье 1» и «Подбарабанье 3») обладают большей сепарирующей способностью по сравнению с подбарабаньем серийного исполнения. Из рисунков 7 и 8 видно, что лучшую сепарацию зерна А $(77,7 \%)$ при меньших затратах мощности обеспечивает «Подбарабанье 1». Более высокую производительность показало МСУ с вариантом «Подбарабанье 1», у которого при потребляемой мощности 7500 Вт была достигнута приведенная подача 0,075 кг'м ${ }^{-1}$. В варианте «Подбарабанье 3 » максимальная приведенная подача при той же мощности составила $0,065 \mathrm{\kappa}^{\cdot} \cdot \mathrm{M}^{-1}$. Сепарирующая способность предлагаемого подбарабанья на 10-15\% выше, чем у серийного. Кроме того, при работе МСУ с дифференцированным подбарабаньем требуется меньше мощности на привод молотильного барабана. Появляется возможность производить обмолот с увеличенными зазорами, что позвояет повысить пропускную способность МСУ. Проведенные поисковые эксперименты позволили определить интервалы варьирования значений факторов при работе МСУ с дифференцированным подбарабаньем: приведенная подача $\mu_{0}=0,045-0,075 \kappa^{\cdot} \mathrm{M}^{-1}$; линейная скорость бичей $v_{6}=20-40 \mathrm{M} \cdot \mathrm{c}^{-1}$; зазор между барабаном и подбарабаньем на входе в МСУ $\Delta_{\mathrm{Bx}}=0,018-0,04 \mathrm{~m}$; зазор между барабаном и подбарабаньем на выходе из МСУ $\Delta_{\text {вых }}=0,002-0,018$ м (Гусаров и др. 2015). 
A.V. Klochkov, V.V. Gusarov, M. Kuboń, J.R. Kamiński

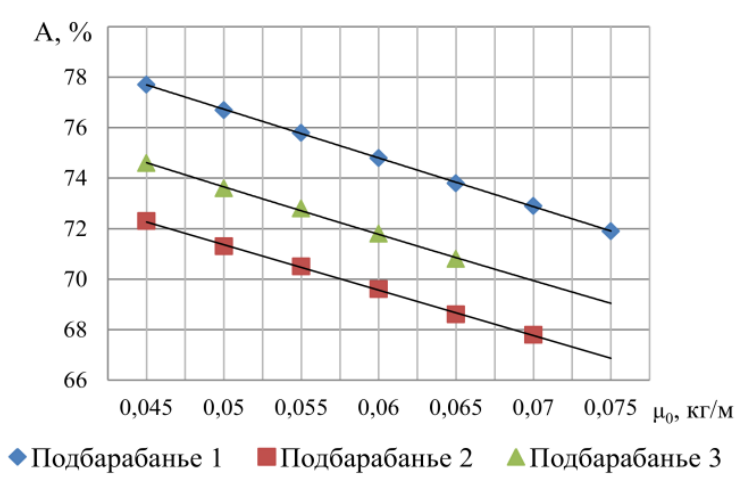

Рисунок 7. Зависимость сепараџии зерна А от приведенной подачи $\mu_{0}$

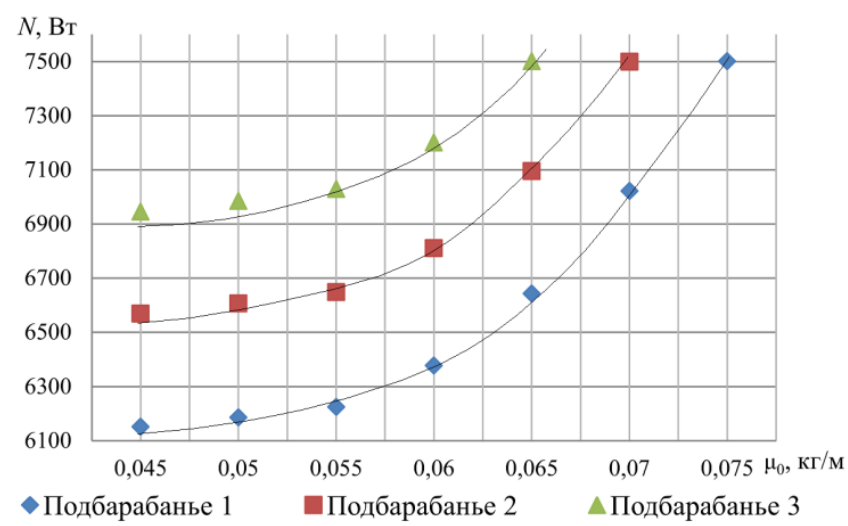

Рисунок 8. Зависимость потребляемой мощңности на привод молотильного барабана $N$ от приведенной подачи $\mu_{0}$

В результате обработки экспериментальных данных получены уравнения регрессии для каждого из результирующих параметров, соответствующие экспериментальным данным (проверка соответствия производилась по критерию Фишера):

- степень выделения зерна через подбарабанье

- степень дробления зерна

$$
\begin{aligned}
\mathrm{B}_{\Delta}=-3,33+0,264 \cdot v_{\sigma}-38,21 \cdot \Delta_{\mathrm{Bx}} & -0,0036 \cdot v_{\sigma}^{2}+897,066 \cdot \Delta_{\mathrm{Bx}}^{2}- \\
& -95,747 \cdot \mu_{0} \cdot \Delta_{\mathrm{Bx}}-112,634 \cdot \Delta_{\mathrm{Bx}} \cdot \Delta_{\text {вых }} ;
\end{aligned}
$$

$$
\begin{aligned}
& Д_{\Delta}=0,0017 \cdot v_{б}-2,116 \cdot \Delta_{\mathrm{Bx}}-0,00018 \cdot v_{\sigma}^{2}+8,05 \cdot \Delta_{\mathrm{Bx}}^{2}+ \\
& \quad+87,105 \cdot \Delta_{\text {вых }}{ }^{2}-0,013 \cdot v_{\sigma} \cdot \Delta_{\text {вх }}-2,074 \cdot \mu_{0} \cdot \Delta_{\mathrm{Bx}}-19,814 \cdot \Delta_{\text {вх }} \cdot \Delta_{\text {вых }} ;
\end{aligned}
$$

- степень чистоты зерна, отсепарированного подбарабаньем

$$
\begin{aligned}
& \mathrm{Ч}_{\Delta}=0,387+8,943 \cdot \mu_{0}+20,424 \cdot \Delta_{\text {вых }}-0,000028 \cdot v_{\sigma}^{2}-77,452 \cdot \mu_{0}{ }^{2}-462,857 \times \\
& \times \Delta_{\text {вых }}{ }^{2}+0,053 \cdot v_{\text {б }} \cdot \Delta_{\text {вх }}-0,086 \cdot v_{\text {б }} \cdot \Delta_{\text {вых }}-57,026 \cdot \mu_{0} \cdot \Delta_{\text {вых }}+54,507 \cdot \Delta_{\text {вх }} \cdot \Delta_{\text {вых }} ;
\end{aligned}
$$

40 
Threshing and grain separating...

- мощность на привод молотильного барабана

$$
\begin{aligned}
N=5062,0+32,77 \cdot v_{\bar{\sigma}} & +22491,78 \cdot \mu_{0}-50861,7 \cdot \Delta_{\text {вых }}-93,33 \cdot v_{\sigma} \cdot \mu_{0}- \\
-435,94 \cdot v_{\sigma} \cdot \Delta_{\text {вых }} & -199102,0 \cdot \mu_{0} \cdot \Delta_{\text {вх }}+282291,7 \cdot \mu_{0} \cdot \Delta_{\text {вых }}+ \\
& +221584,5 \cdot \Delta_{\text {вх }} \cdot \Delta_{\text {вых }} .
\end{aligned}
$$

Из анализа уравнений регрессии второго порядка (17-20) определены координаты оптимума и изучены свойства поверхностей отклика в окрестностях оптимума. Для каждого параметра определены оптимальные значения. Так, для степени выделения зерна $\mathrm{B}_{\Delta}$ оптимальные значения составляют: $v_{б}=36 \mathrm{~m} \cdot \mathrm{c}^{-1} ; \mu_{0}=0,045 \mathrm{\kappa}^{\cdot} \cdot \mathrm{m}^{-1} ; \Delta_{\mathrm{Bx}}=$ $0,018 \mathrm{м} ; \Delta_{\text {вых }}=0,002 \mathrm{м}$, при этом $\mathrm{B}_{\Delta}=0,936$ (93,6 \%). Для степени дробления Д оптимальные значения: $v_{б}=20 \mathrm{M} \cdot \mathrm{c}^{-1} ; \mu_{0}=0,051 \mathrm{\kappa} \Gamma \cdot \mathrm{M}^{-1} ; \Delta_{\mathrm{Bx}}==0,040 \mathrm{M} ; \Delta_{\mathrm{Bыx}}=0,017 \mathrm{M}$, при этом Д $Д_{\Delta}=0$. Для степени чистоты зерна Ч ${ }_{\Delta}$ оптимальные значения: $v_{б}=20 \mathrm{M} \cdot \mathrm{c}^{-1}$; $\mu_{0}=0,053 \kappa \Gamma^{\cdot} \mathrm{M}^{-1} ; \Delta_{\text {вх }}=0,040 \mathrm{M} ; \Delta_{\text {вых }}=0,018 \mathrm{м}$, при этом $\mathrm{Ч}_{\Delta}=0,855(85,5 \%)$. Для мощности на привод молотильного барабана $N$ оптимальные значения: $v_{\sigma}=20 \mathrm{~m} / \mathrm{c} ; \mu_{0}$ $=0,045 \kappa \Gamma^{\cdot} \mathrm{M}^{-1} ; \Delta_{\text {вх }}=0,040 \mathrm{м} ; \Delta_{\text {вых }}=0,018 \mathrm{м}$, при этом $N=5604$ Вт (Гусаров и др. 2015).

Двумерные сечения (Рисунок 9) построены по выражению (17) для параметра степени выделения зерна, принятого основным.
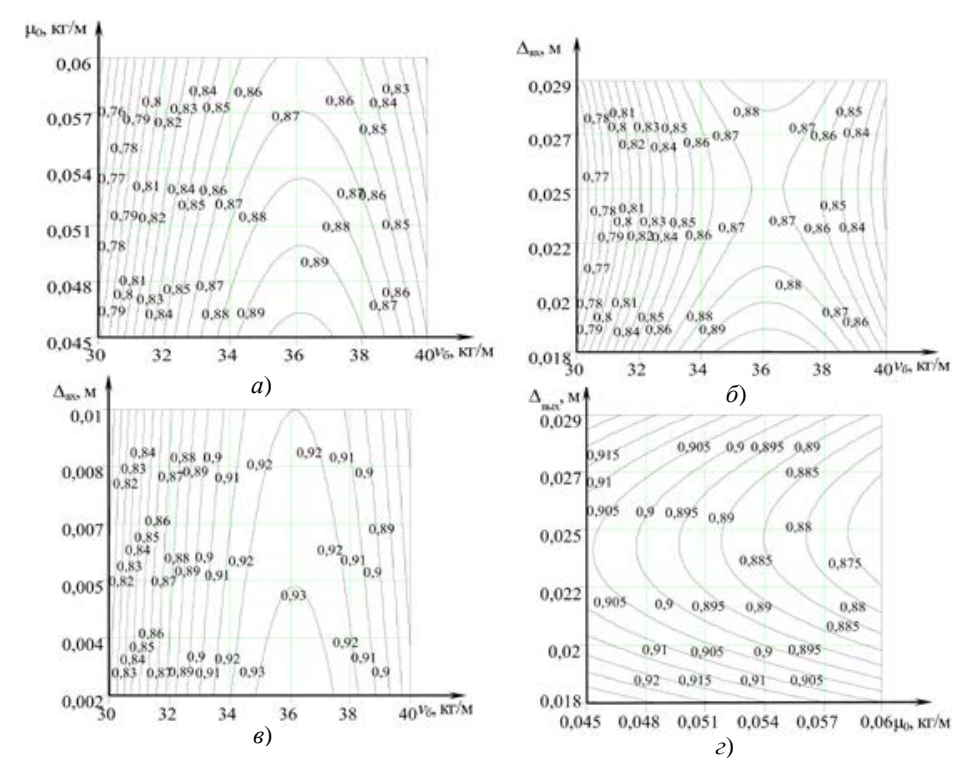

$a-\mu_{0}$ и $v_{\bar{\sigma}} ; \sigma-\Delta_{\mathrm{BX}}$ и $v_{\bar{\sigma}} ; в-\Delta_{\text {вых }}$ и $v_{\bar{\sigma}} ; 2-\Delta_{\mathrm{BX}}$ и $\mu_{0}$.

Рисунок 9. Двумерные сечения поверхностей отклика степени выделения зерна дифференцированным подбарабаньем при сочетаниях действующих факторов

Источник: Разработка авторов на основе собственных исследований. 
Анализируя полученные графические зависимости параметра степени выделения зерна, можно отметить следующее:

- факторами, оказывающими наибольшее влияние на степень выделения зерна, являются приведенная подача и линейная скорость бичей, а также зазор на выходе из МСУ;

- область оптимума значений исследуемых факторов находится в пределах: приведенная подача - 0,045-0,06 кг· $\mathrm{m}^{-1}$; линейная скорость бичей $-30-40 \mathrm{~m} \cdot \mathrm{c}^{-1}$; зазор на выходе из МСУ - 0,002-0,010 м. С помощью математического программирования решена компромиссная задача для целевой функции:

$$
\begin{gathered}
\mathrm{B}_{\Delta}=-3,33+0,264 \cdot v_{6}-38,21 \cdot \Delta_{\mathrm{Bx}}-0,0036 \cdot v_{\sigma}{ }^{2}+897,066 \cdot \Delta_{\mathrm{Bx}}{ }^{2}- \\
-95,747 \cdot \mu_{0} \cdot \Delta_{\mathrm{Bx}}-112,634 \cdot \Delta_{\mathrm{Bx}} \cdot \Delta_{\mathrm{Bdx}} \rightarrow \max .
\end{gathered}
$$

Решение оптимизационной задачи для целевой функции (21) выражений (18)-(20) произведено в Microsoft Excel с помощью надстройки «Поиск решения».

Полученные результаты показывают, что в МСУ с дифференцированным подбарабаньем по принятым показателям качества выполнения технологического процесса выделение зерна подбарабаньем составляет 87,6\%, дробление зерна - 0,8\%, чистота зерна - 78,0\% при значениях $v_{\sigma}=36 \mathrm{M}^{\cdot} \cdot \mathrm{c}^{-1} ; \mu_{0}=0,055 \mathrm{\kappa}^{\cdot} \cdot \mathrm{M}^{-1} ; \Delta_{\mathrm{Bx}}=0,029 \mathrm{M}$; $\Delta_{\text {вых }}=0,01 \mathrm{M}$.

\section{Расчет экономической эффективности}

Приведены результаты сравнительных испытаний зерноуборочных комбайнов серийного исполнения и комбайна, имеющего МСУ с дифференцированным подбарабаньем. Отмечено увеличение пропускной способности по зерностебельной массе на 26,0\% при эксплуатации зерноуборочного комбайна с дифференцированным подбарабаньем, повышение производительности на 27,1\%, снижение потерь за соломотрясом на 23,2\% (Гусаров, 2013).

Описана реализация результатов исследований. Результаты исследований по диссертационной работе рассмотрены Республиканским конструкторским унитарным предприятием «ГСКБ по зерноуборочной и кормоуборочной технике» и приняты к использованию при разработке конструкций зерноуборочных комбайнов. На основании теоретических исследований РКУП «ГСКБ по зерноуборочной и кормоуборочной технике» разработана техническая документация на изготовление дифференцированного подбарабанья и изготовлена опытная партия в количестве 2 шт. с последующим выпуском в 2013 г. 10 комбайнов КС3-1218 «ПАЛЕССE GS12» с дифференцированным подбарабаньем.

Приведен расчет экономической эффективности внедрения MCУ c дифференцированным подбарабаньем. При использовании дифференцированного подбарабанья годовая экономия затрат труда составила 47,74 человеко-часов, степень снижения себестоимости механизированных работ - 24,4\%, снижение расхода топлива $-8,2 \%$. В итоге годовой приведенный экономический эффект составил 158,1 млн. рублей (в ценах на 01.11.2013) (Гусаров и др., 2014). 
Threshing and grain separating...

\section{Заключение}

1. Полученые аналитические зависимости, позволяющие определить площади сечений характерных зон воздействия МСУ на обмолачиваемую массу, на основании которых определены конструктивно-технологические параметры дифференцированного подбарабанья: окружное усилие, возникающее при движении порции обмолачиваемой массы; число поперечных планок (15 шт.); минимальное расстояние между поперечными планками $\left(53,5 \cdot 10^{-3} \mathrm{M}\right)$; максимальная высота поперечной планки относительно продольных прутков $\left(26 \cdot 10^{-3} \mathrm{M}\right)$.

2. Установлены закономерности деформации изгиба массы в характерных зонах воздействия МСУ на обмолачиваемую массу. Изгиб стеблей зависит от расстояния между планками подбарабанья, при этом оказывает влияние также и то, какая часть стеблей подвергается изгибу. Удельные энергозатраты на изгиб стеблей более значительны при расстоянии между планками $(50-80) \cdot 10^{-3}$ м и составляют (2-10) $10^{-3}$ Дж· $\mathbf{M}^{-1}$. При увеличении расстояния между планками свыше (90-120) $10^{-3}$ м энергозатраты стабилизируются на уровне до $(1,5-2,0) \cdot 10^{-3}$ Дж· ${ }^{-1}$.

3. Получены уравнения регрессии, описывающие процесс работы МСУ с дифференцированным подбарабаньем, которые позволили определить, что максимальное выделение зерна подбарабаньем $87,6 \%$ достигается при оптимальных значениях основных факторов: линейная скорость бичей $-36 \mathrm{~m} \cdot \mathrm{c}^{-1}$; приведенная подача $-0,055 \kappa^{\cdot} \mathrm{M}^{-1}$; зазор между поперечной планкой и барабаном на входе в МСУ $-29 \cdot 10^{-3}$ м; зазор между поперечной планкой и барабаном на выходе из МСУ $-10 \cdot 10^{-3}$ м.

4. Научно обоснована и создана конструкция подбарабанья, отличающаяся дифференцированным расположением поперечных планок, и их высотой относительно продольных прутков: расстояние между поперечными планками у дифференцированного подбарабанья изменяется от $79,5 \cdot 10^{-3}$ м до $53,5 \cdot 10^{-3}$ м с шагом $2 \cdot 10^{-3}$ м, высота планок относительно прутков изменяется от $12 \cdot 10^{-3}$ м до $26 \cdot 10^{-3}$ м с шагом $1 \cdot 10^{-3}$ м, что позволяет увеличить сепарацию зерна через подбарабанье с выполнением требований качества, предъявляемых к обмолоту сельскохозяйственных культур зерноуборочными комбайнами (Клочков и др., 2012; Гусаров и др., 2013; 2014; 2015).

5. Испытаниями модернизированного зерноуборочного комбайна КЗС-10K «ПАЛЕCCE GS10» в производственных условиях подтверждена эффективность MCУ с дифференцированным подбарабаньем, обеспечивающим увеличение пропускной способности по зерностебельной массе на $26,0 \%$, производительности на $27,1 \%$, снижение потерь за соломотрясом на $23,2 \%$, потерь за решетами на 3,3\%. В целом, снижение потерь за МСУ достигло 17,8\%. 


\section{Литература}

Bułgakov, V., Shpokas, L., Petkavichius, S. (2006). Исследования уборки кукурузы на зерно. (The investigation of long stern maize threshing process). MOTROL, 8, 58-68.

Golka, (red.). (2016). Trends of technique development in agricultural transport, soil tillage, seeding, fertilization and plant protection. Inżynieria w Rolnictwie. Monografie nr 23. ISSN 2083-9545, ss. 138.

Гусаров, В. В. (2013). Сравнительные показатели работы зерноуборочного комбайна с дифференцированной рабочей поверхностью подбарабанья молотильного аппарата. Вестник Белорусской государственной сельскохозяйственной академии. № 3, 132-137.

Гусаров, В. В., Клочков, А. В., Липская, В. К. (2014). Технико-экономические аспекты применения дифференцированного подбарабанья зерноуборочного комбайна ПАЛЕССЕ GS10 в производственных условиях. Вестник Белорусской государственной сельскохозяйственной академии. № 1, 167-171.

Гусаров, В. В., Курзенков, С. В. (2015). Результаты экспериментальных исследований процесса обмолота бильным молотильным аппаратом с дифференцированным подбарабаньем. Вестник Белорусской государственной сельскохозяйственной академии. № 3, 182-188.

Гусаров, В. В., Клочков, А. В., Курзенков, С. В. (2015). Параметры зон воздействия молотильно-сепарируищего устройства на обмолачиваемую массу. Вестник Белорусской государственной сельскохозяйственной академии. № 3, 175-181.

Гусаров, В. В., Гусаров, И. В. (2014). Сравнительные показатели работы зерноуборочного комбайна КЗС 10К с дифференцированной рабочей поверхностью подбарабанья молотильного аппарата. Конструирование, использование и надежность машин сельскохозяйственного назначения: сборник научных трудов. Брянск. Брянская государственная сельскохозяйственная академия. № 3, 31-35.

Dębska, A., Bieniek, J,. Fabrykowski, E., Molendowski, F., Romański, L. (2016). Exploitation assessment of New Holland CX780 Combine harvester. Agricultural Engineering. Vol. 20. Nr 2, 43-51.

Kamiński, E. (red.). (2011). Development trends in soil fertilization engineering in the aspect of organic farming standards. Instytut Technologiczno-Przyrodniczy. Falenty. ISBN 978-83-6241626-7.

Kamiński, J. R., Kruk, I. S., Szeptycki, A. (2015). Tractor-machine sets in modern agriculture. Inżynieria w Rolnictwie. Monografie nr 18.

Клочков, А. В., Дюжев, А. А., Гусаров, В. В. (2012). Зерноуборочные комбайны: этапы совершенствования, современное состояние, перспективы развития. Монография. БГСХА Горки.

Клочков, А. В., Гусаров, В. В. (2009). Намолоты зерноуборочными комбайнами в хозяйствах Республики Беларусь. Вестник Белорусской государственной сельскохозяйственной академии. № 1, 138-143.

Клочков, А. В., Рехлицкий, О. В., Гусаров, В. В., Ковалевский, В. Ф. (2013). Показатели использования зерноуборочных комбайнов «Полессе GS» в хозяйствах Беларуси. Вестник Белорусской государственной сельскохозяйственной академии. № 1, 105-110.

Knapik, A. (1994). The of vibrations in model diagnosis research of the separator drum. W: Rozwój teorii i technologii w technicznej modernizacji rolnictwa. III Ogólnopolska i II Międzynarodowa Konferencja Naukowa. Akademia Rolniczo-Techniczna w Olsztynie 22-23 września 1994, s. 25-28.

Letoszniew, M. (1953). Maszyny rolnicze. Państwowe Wydawnictwo Rolnicze i Leśne. Warszawa.

Липкович, Э. И. (2004). Обоснование эффективности производства зерна в условиях рыночной экономики. Механизация и электрификация сельского хозяйства. №4, 2-4. 
Threshing and grain separating...

Miłosz, T. 2000. Zespoły młócaco-wydzielajace i czyszczace w kombajnach do zbioru zbóż. IBMER Warszawa. ISBN 83-86264-67-5.

Molendowski, F. (2001). Ocena eksploatacyjna kombajnu zbożowego CASE 2188. Inżynieria Rolnicza,12(32), 214-218.

Molendowski, F. (2006). Comparison testing of the cob_pickers BOURGOIN JDL 410D and BOURGOIN GX406A. Inżynieria Rolnicza, 3(78), 327-333.

Molendowski, F., Bieniek, J., Górnik, Ł., Worobiec, G. (2011a). Assessment of the selected lawnmowers and garden strimmers. Inzynieria Rolnicza, 9(134), 131-136.

Molendowski, F., Romański, L., Hutnik, K. (2011b). Comparative assessment of New Holland CS 6070 combine harvester with Bizon Rekord Z-058 combine. Inżynieria Rolnicza, 8(133), 223228.

Molendowski, F., Romański, L., Górnik, Ł. (2012). Exploitation evaluation of the selected combine harvesters for harvesting grain with the complex index method. Inzynieria Rolnicza, 4(139), $277-$ 284.

Mulka, C., Molendowski, F., Siwiec, L. (1996). Badania porównawcze kombajnów Claas Dominator 108, John Deere 1188 i Bizon Gigant Z-060. Zeszyty Naukowe Akademii Rolniczej we Wrocławiu. Mechanizacja rolnictwa IV. 302, 175-181.

Szymanek, M., Dreszer, K. (2011). The impact of threshing units on maize kemel separation rates and losses). Inżynieria Rolnicza, 4(129), 289-294.

Зайцев, А.А. (2002). Анализ и синтез дифференцированного процесса обмолота и создание средств его реализации. Российский государственный аграрный заочный университет. Балашиха, докторская диссертация сс. 386.

\section{URZĄDZENIE MLÓCACCO-SEPARUJĄE KOMBAJNU ZE ZMIENNA SZCZELINA NAD KLEPISKIEM INTENSYFIKUJĄCĄ OMLOT I CZYSZCZENIE ZIARNA}

Streszczenie. Celem badań była intensyfikacja procesu omłotu i separacji ziarna bębnowym młócącoseparującym urządzeniem kombajnu zbożowego, mającym zmienną szczelinę nad klepiskiem. Określenie racjonalnej konstrukcji i parametrów szczeliny klepiska, a także reżimów pracy bębna młócącego. Rozważania teoretyczne prowadzono na bazie zasad mechaniki, a eksperymenty w oparciu o metodyki ogólne i specjalne. Do obróbki wyników wykorzystano metody standardowe obliczeń i pakiety praktycznych programów Microsoft Excel i MathCAD. Do pomiarów wykorzystano aparaturę pomiarowo-rejestrującą. Badania eksperymentalne prowadzono na specjalnie przygotowanych eksperymentalnych stanowiskach. Przeprowadzone badania pozwoliły: uzasadnić konstrukcyjnotechnologiczne schematy bębna młócącego ze zmienną szczeliną nad klepiskiem, znaleźć analityczne zależności dla określenia charakterystycznych zakresów powierzchni oddziaływania bębna młócacego i klepiska na młóconą masę, ustalić zasady odkształcania słomy pod działaniem różnych sił przy zmiennym rozstawie między poprzecznymi listwami klepiska, otrzymać równania regresji, pozwalające określić optymalne technologiczne parametry pracy bębna młócącego ze zmienną szczeliną nad klepiskiem. Nowość naukowa opracowanych rozwiązań technicznych została potwierdzona patentem Republiki Białoruskiej na wzór użytkowy Nr 6335 „Bęben młócący”. Rezultaty teoretycznych i eksperymentalnych badań wykorzystano podczas opracowania dokumentacji konstrukcyjnej do wykonania drgającego klepiska do kombajnów produkcji ПО «Гомсельмаш».

Słowa kluczowe: kombajn zbożowy, urządzenie młócąco-separujące, klepisko, omłot, separacja 